\title{
Antibiotic resistance pattern of Shiga-toxigenic Escherichia coli isolated from ready-to-eat food stuffs
}

\author{
Mohammad Hossein Sakhaie Shahreza', Ebrahim Rahimi ${ }^{2 *}$ and Hassan Momtaz \\ ${ }^{1}$ Student of Veterinary Medicine, College of Veterinary Medicine, Shahrekord Branch, Islamic Azad \\ University, Shahrekord, Iran \\ ${ }^{2}$ Department of Food Hygiene and Public Health, College of Veterinary Medicine, Shahrekord Branch, Islamic \\ Azad University, Shahrekord, Iran \\ ${ }^{3}$ Department of Microbiology, College of Basic Sciences, Shahrekord Branch, Islamic Azad University, \\ Shahrekord, Iran
}

\begin{abstract}
Shiga toxigenic Escherichia coli are the most important causes of food-borne diseases due to the consumption of contaminated ready to eat foods. The present investigation was done to study the prevalence rate and antibiotic resistance pattern of STEC strains recovered from various types of ready to eat foods. Seven-hundred and twenty various types of food samples were collected and cultured. Isolated E. coli strains were approved another time using PCR. Approved colonies were tested for antibiotic susceptibility using the disk diffusion. Twenty-six out of 720 food samples (5.20\%) were positive for E. coli strains. Prevalence of STEC strains were 1.52\%. Salad (15\%) had the highest prevalence of bacteria, while hamburger (2.50\%) had the lowest. STEC strains exhibited the highest levels of resistance against tetracycline (100\%), ampicillin (100\%), gentamicin (81.81\%) and ciprofloxacin (72.72\%), while exhibited the lowest against chloramphenicol (27.27\%) and cotrimoxazole (45.45\%). High prevalence of resistant STEC strains in ready to eat foods showed irregular prescription of antibiotic as well as lack of proper hygiene in restaurant and fast food centers. Cautious prescription of antibiotics and attentions to the principles of food security can decrease the risk of resistant STEC strains in ready to eat foods.
\end{abstract}

KEY WORDS: SHIGA TOXIGENIC ESCHERICHIA COLI, PREVALENCE, ANTIBIOTIC RESISTANCE, READY TO EAT FOODS

\author{
ARTICLE INFORMATION: \\ *Corresponding Author: Ebrahimrahimi55@yahoo.com \\ Received $15^{\text {th }}$ May, 2017 \\ Accepted after revision $17^{\text {th }}$ June, 2017 \\ BBRC Print ISSN: 0974-6455 \\ Online ISSN: 2321-4007 CODEN: USA BBRCBA \\ . Thomson Reuters ISI ESC and Crossref Indexed Journal \\ NAAS Journal Score 2017: 4.31 Cosmos IF : 4.006 \\ $\odot$ A Society of Science and Nature Publication, 2017. All rights \\ reserved. \\ Online Contents Available at: http//www.bbrc.in/
}




\section{INTRODUCTION}

Food hygiene in restaurants and fast-foods are one of the most important critical issues in the society. Using from low quality raw materials, cooking of foods more than daily requirement and their storage in unsuitable conditions and finally lack in the observation of proper hygiene in cooking of foods are the main factors causing enhancement of microbial spoilage and growth of dangerous food-borne pathogens in foods (Isara and Isah, 2009). Among all pathogenic agents causing foodborne diseases and food poisoning, Escherichia coli (E. coli) strains had a significant importance (Momtaz et al. 2012; Momtaz et al. 2013). is a gram-negative, non-sporulating, flagellated, rod-shaped and facultative anaerobic bacterium which belongs to Enterobacteriaceae family. Shiga (vero) toxin (Stx)-producing $E$. coli (STEC) is a subdivision of an important pathogenic group of this bacterium named enterohemorrhagic $E$. coli (EHEC) (Momtaz et al. 2012; Momtaz et al. 2013; Dehkordi et al. 2014). STEC strains are responsible for intensive clinical syndromes like lethal hemolytic uremic syndrome (HUS), bloody and non-bloody diarrhea, thrombotic thrombocytopenic purpura (TTP) and hemorrhagic colitis (HC) (Momtaz et al. 2012; Momtaz et al. 2013; Dehkordi et al. 2014 and Ranjbar et al. 2017).

High levels of resistance in STEC strains is another important factor which increase the pathogenicity of bacteria. Unfortunately, STEC strains recovered from food stuffs and also cases of diarrhea and food poisoning harbored the high levels of resistance against commonly used groups of antibiotics including quinolones, aminoglycosides, macrolides, cephalosporins, sulfonamides, fluoroquinolones and tetracycline (Momtaz et al. 2013b; Momtaz et al. 2013c; Stewardson et al. 2014; Amézquita-López et al. 2016). In the other hands, STEC strains of food poisoning show a high incidence of resistance (85-100\%) against commonly used antimicrobial agents (Momtaz et al. 2013b; Momtaz et al. 2013c; Stewardson et al. 2014; Amézquita-López et al. 2016).

\section{MATERIALS AND METHODS}

The study was approved by the Ethical Committee of Islamic Azad University, Shahrekjord Branch (Consent Ref Number IAU 2053). Verification of this research project and the licenses related to sampling process were approved by the Prof. EbrahimRahimi (Approval Ref Number Food-Hygiene 95 2020). From September 2013 to September 2014, a total of 720 various types of readyto-eat foods including sausage $(n=70)$, salami $(n=70)$, hamburger $(n=60)$, roast mouthful $(n=60)$, traditional dressing $(n=65)$, traditional salad $(n=60)$, traditional candy $(n=60)$, traditional ice-cream $(n=60)$, barbecue $(n=70)$, soup $(n=75)$ and spices $(n=70)$ were randomly collected from various restaurant in the Isfahan province, Iran. Samples were immediately transferred to laboratory in cooler with ice-packs.

Totally, 10-g of crushed food samples were homogenized for $2 \mathrm{~min}$ in $90 \mathrm{ml}$ of Peptone Water (PW, Merck, Germany). Then the samples were cultured on 5\% sheep blood and MacConkey agar (Merck, Germany) and incubated for 18 to $24 \mathrm{~h}$ at $37{ }^{\circ} \mathrm{C}$. Colonies with the typical color and appearance of $E$. coli were picked and streaked again on blood agar plates and re-streaked on EMB agar (Merck, Germany). All plates were further incubated for $24 \mathrm{~h}$ at $37{ }^{\circ} \mathrm{C}$. The green metallic sheen colonies were considered as $E$. coli. The presumptive colonies were biochemically tested for growth on triple sugar iron agar (TSI) and lysine iron agar (LIA), oxidative/fermentative degradation of glucose, citrate utilization, urease production, indol fermentation, tryptophan degradation, glucose degradation (methyl red test) and motility. Bacterial strains were sub-cultured overnight in Luria-Bertani broth (Merck, Germany) and further incubated for 48 $\mathrm{h}$ at $37^{\circ} \mathrm{C}$. Genomic DNA was extracted from bacterial colonies using the DNA extraction kit (Fermentas, Germany) according to manufacturer's instruction. Bacterial colonies were further confirmed using the 165 rRNA-based Polymerase Chain Reaction (PCR) (Woo et al. 2001) Set of primers used for this purpose are Forward: 5'-AGTTTGATCCTGGCTCAG-3' and Reverse: 5'-AGGCCCGGGAACGTATTCAC-3' (1343 bp). Prevalence of STEC strains was determined according to the method described by SafarpoorDehkordi et al. (2014) and Momtaz et al. (2013a).

Pattern of antimicrobial resistance was studied using the simple disk diffusion technique on Mueller-Hinton agar (Merck, Germany). Susceptibility of STECstrains were tested against tetracycline (30 u/disk), ampicillin (10 u/disk), cefotaxime (30 $\mathrm{gg} /$ disk), gentamycin (10 $\mu \mathrm{g} /$ disk), ciprofloxacin (5 $\mathrm{gg} /$ disk), cotrimoxazole $(30 \mu \mathrm{g} /$ disk), enrofloxacin(5 $\mu \mathrm{g} /$ disk), trimethoprim(5 $\mathrm{gg} /$ disk), and chloramphenicol (30 $\mu \mathrm{g} /$ disk) antibiotic agents (Oxoid, UK). All of the inoculated plates were aerobically incubated at $37{ }^{\circ} \mathrm{C}$ for $18-24 \mathrm{~h}$. Results were interpreted based on the instruction provided by CLSI (2012) (Wayne 2012). E. coli ATCC 25922 was used as quality control. Statistical analysis was performed using SPSS/16.0 software for significant relationships. The incidence of antibiotics resistance of STEC isolated from various types of ready-to-eat food samples were statistically analyzed. Statistical significance was regarded at a value $<0.05$. 


\section{RESULTS AND DISCUSSION}

The present investigation was done in order to assess the prevalence of E. coli and STEC strains as well as study the antibiotic resistance pattern of isolated bacteria. Table 1 represents the total prevalence of E. coli and STEC strains isolated from various types of ready to eat foods. Twenty-six out of 720 food samples (5.20\%) were positive for E. coli strains. Among all $26 \mathrm{E}$. coli strains, 11 strains (42.30\%) were considered as STEC strains. Salad (15\%), candy (12.50\%) and barbecue (10\%) were the most commonly contaminated samples. There were no positive results for Sausage, salami, roast mouthful and soup samples. Statistically significant differences were seen between the types of samples and prevalence of STEC strains $(<0.05)$.
Table 2 represents the antibiotic resistance pattern of STEC strains isolated from various types of ready to eat food samples. We found that STEC strains harbored the highest levels of resistance against tetracycline (100\%), ampicillin (100\%), gentamicin (81.81\%) and ciprofloxacin (72.72\%). Resistance against chloramphenicol (27.27\%) and cotrimoxazole (45.45\%) were low. Statistically significant differences were seen between the types of samples and prevalence of antibiotic resistance $(p<0.05)$.

The present investigation showed that resistant STEC strains had a considerable prevalence in various types of ready to eat food samples. Total prevalence of E. coli and also STEC strains among the food samples of our study were $5.20 \%$ and $1.52 \%$, respectively which emerged an important public health issue regarding the consumption of ready to eat foods.

\begin{tabular}{|c|c|c|c|c|}
\hline Types of samples & $\begin{array}{l}\text { No. samples } \\
\text { collected }\end{array}$ & $\begin{array}{l}\text { No positive } \\
\text { strains (\%) }\end{array}$ & $\begin{array}{l}\text { PCR confirmation } \\
(\%)\end{array}$ & STEC strains (\%) \\
\hline Sausage & 70 & - & - & - \\
\hline Salami & 70 & - & - & - \\
\hline Hamburger & 60 & $1(2.50)$ & $1(2.50)$ & $1(100)$ \\
\hline Roast mouthful & 60 & - & - & - \\
\hline Dressing & 65 & $4(8)$ & $4(8)$ & $1(25)$ \\
\hline Salad & 60 & $6(15)$ & $6(15)$ & 2 (33.33) \\
\hline Candy & 60 & $5(12.50)$ & $5(12.50)$ & $1(20)$ \\
\hline Ice cream & 60 & $2(5)$ & $2(5)$ & $2(100)$ \\
\hline Barbecue & 70 & $5(10)$ & $5(10)$ & $2(40)$ \\
\hline Soup & 75 & - & - & - \\
\hline Spices & 70 & $3(5)$ & $3(5)$ & 2 (66.66) \\
\hline Total & 720 & $26(5.20)$ & $26(5.20)$ & $11(42.30)$ \\
\hline
\end{tabular}

Table 2. Total distribution of antibiotic resistance pattern of STEC strainsisolated from various types of ready to eat food samples.

\begin{tabular}{|c|c|c|c|c|c|c|c|c|c|}
\hline \multirow{2}{*}{$\begin{array}{l}\text { Samples (No. } \\
\text { STEC strains) }\end{array}$} & \multicolumn{9}{|c|}{ Antibiotic resistance pattern (\%) } \\
\hline & Tet $^{*}$ & Amp & Cef & Gen & Cip & Cot & Enr & Tri & $\mathrm{C} 30$ \\
\hline Hamburger (1) & $1(100)$ & $1(100)$ & $1(100)$ & $1(100)$ & $1(100)$ & $1(100)$ & $1(100)$ & $1(100)$ & $1(100)$ \\
\hline Dressing (1) & $1(100)$ & $1(100)$ & $1(100)$ & $1(100)$ & $1(100)$ & - & - & - & - \\
\hline Salad (2) & $2(100)$ & $2(100)$ & $1(50)$ & $1(50)$ & $1(50)$ & $1(50)$ & $1(50)$ & $1(50)$ & - \\
\hline Candy (1) & $1(100)$ & $1(100)$ & - & $1(100)$ & $1(100)$ & - & $1(100)$ & $1(100)$ & - \\
\hline Ice cream (2) & $2(100)$ & $2(100)$ & $1(50)$ & $2(100)$ & $1(50)$ & $1(50)$ & $1(50)$ & $1(50)$ & - \\
\hline Barbecue (2) & $2(100)$ & $2(100)$ & $2(100)$ & $2(100)$ & $2(100)$ & $1(50)$ & $1(50)$ & $1(50)$ & $2(100)$ \\
\hline Spices (2) & $2(100)$ & $2(100)$ & $1(50)$ & $1(50)$ & $1(50)$ & $1(50)$ & $1(50)$ & $1(50)$ & - \\
\hline Total (11) & $11(100)$ & $11(100)$ & 7 (63.63) & 9 (81.81) & 8 (72.72) & $5(45.45)$ & $6(54.54)$ & $6(54.54)$ & $3(27.27)$ \\
\hline
\end{tabular}


There were some likelyexplanations for the high prevalence of E. coli and also STEC strains in the ready to eat food samples. At first. high-volume food production and long process of catering caused several problems such as lack of adequate precision and accuracy in the preparation and washing of raw materials and even their well cooking, lack of enough time and even temperature for cooking of raw materials, cooling of foods during processing, lack of reaching of sufficient heat to the center of meat and other food materials, lack of enough time to withdraw meat from the frozen state and finally cooking of meat and its products more than the daily requirement and then their storage at improper temperature and conditions. These mentioned circumstances maybe lead to survival and even growth of pathogenic microorganisms in ready to eat foods. At second, using from unsanitary and also contaminated equipment and dishes for production of foods in restaurant and fast food centers. At third, presence of infected staffs which maybe the sources of dangerous pathogenic agentsin the food processing stage (Shahrani et al. 2014; Hemmatinezhad et al. 2015; Ranjbar et al. 2017).

Sausage, salami and roast mouthful are mainly produced in high temperature and also they have been presented in a hygienic package. Therefore, it is not surprising that all of these samples were free from $E$. coli. High temperature using for cooking of soup make it clean from any pathogenic agents like $E$. coli. Because the large numbers of $E$. coli isolates recovered from raw meat, proper preparation of the raw meat can eliminate the distribution of bacteria. Unfortunately, principles of meat inspections were not observed in Iranian slaughterhouses. Therefore, close contact of animal carcasses with each other and even slaughterhouse floor, blood, content of the digestive tract and wool and skin of slaughtered animal caused transmission and distribution of pathogenic agents like E. coli to meat of slaughtered animals. Besides, the role of possible colonizers such as meat inspectors, butchers and miscellaneous people which mainly have come into the slaughterhouse for buying of meat and finally animals like rats, cats and birds which have been entered from outside the slaughterhouse as a sources of pathogenic E. coli should not be overlooked. Survival of STEC strains of raw food samples even after cooking procedure and occurrence of cross contamination after cooking procedure are two important routes of hospital foods contamination (Shahrani et al. 2014; Hemmatinezhad et al. 2015; Ranjbar et al. 2017).

High prevalence of resistance against commonly used antibiotic agents is another important finding of this study. We found that STEC strains harbored the high levels of resistance against tetracycline, ampicillin, cefotaxime, gentamycin, ciprofloxacin, cotrimoxazole, enrofloxacin, trimethoprim and chloramphenicol antibiotics.
Indiscriminate and unauthorized prescription of antibiotics especially in the field of veterinary caused such high prevalence of antibiotic resistance in STEC strains recovered from foods (Shahrani et al. 2014; Hemmatinezhad et al. 2015; Ranjbar et al. 2017).

Several studies have been done in this field in various parts of the world. Miri et al. (2014) reported that from a total of 190 food samples, four samples (2.1\%) were contaminated with $E$. coli. All of the E. coli strains were isolated from hamburger samples (3.3\%). They found that all isolates (100\%) were resistant to one or more antimicrobial agents and especially tetracycline and ampicillin.Srinivasan et al. (2007) showed that all of the $E$. coli strains of food samples exhibited resistance to five or more antimicrobial agents and especially ampicillin, aztreonam, cefaclor, cephalothin, cinoxacin, and nalidixic acid which was similar to us. Kalantar et al. (2013) reported that a total of $87 \mathrm{E}$. coli strains were detected from 466 rectal swabs from children with acute diarrhea and $40 \mathrm{E}$. coli strains were detected from the 125 frozen food samples of animal origin. They showed that consumption of contaminated foods may play an important role in occurrence of $E$. coli infections in children. Stewardson et al. (2014) reported that the prevalence of susceptibility of E. coli strains of food samples against meropenem, gentamicin, ciprofloxacin, cotrimoxazole, and fosfomycinin Switzerland were 100\%, 90\%, 87\%, $79 \%$, and $98 \%$, respectively.

\section{CONCLUSION}

In conclusions, we identified a large number of STEC strains which were resistant against several types of antibiotic agents. Resistance against ampicillin, gentamycin andtetracycline and presence of multidrug resistant strains were the most commonly detected characters in the STEC strains of ready to eat foods. It seems that there were no severemanagements on the principles of food hygiene in Iranian restaurant and fast food centers. Due to the low levels of STEC resistance against chloramphenicol and cotrimoxazole, occurrence of food poisonings due to the STEC strains in tested Iranian restaurant and fast food centers can be treated with their regular prescription. Attentions to the results of disk diffusion method and principles of hazard analysis and critical control point (HACCP) system can reduce the risk of STEC strains in food stuffs.

\section{ACKNOWLEDGEMENTS}

The authors would like to thank Prof. Amir Shakerian at the Department of Food Hygiene, Shahrekord Branch, 
Isamic Azad University, Shahrekord, Iran for his important technical support. This work was supported by the Islamic Azad University, Shahrekjord Branch (Ref Number IAU-Bud-177)

\section{REFERENCES}

Amézquita-López, B. A., Quiñones, B., Soto-Beltrán, M., Lee, B. G., Yambao, J. C., Lugo-Melchor, O. Y. and Chaidez, C. (2016): Antimicrobial resistance profiles of Shiga toxin-producing Escherichia coli 0157 and Non-0157 recovered from domestic farm animals in rural communities in Northwestern Mexico. Antimicrob Resist Infect Control. 5, 1.

Dehkordi, F. S., Yazdani, F., Mozafari, J. and Valizadeh, Y. (2014): Virulence factors, serogroups and antimicrobial resistance properties of Escherichia coli strains in fermented dairy products. BMC Res Note. 7, 1.

Hemmatinezhad, B., Khamesipour, F., Mohammadi, M., Safarpoor Dehkordi, F. and Mashak, Z. (2015): Microbiological Investigation of 0-Serogroups, Virulence Factors and Antimicrobial Resistance Properties of Shiga Toxin-Producing Escherichia coli Isolated from Ostrich, Turkey and Quail Meats. J Food Safety. 35, 491-500.

Isara, A. R. and Isah, E. C.(2009): Knowledge and practice of food hygiene and safety among food handlers in fast food restaurants in Benin City, Edo State. Niger Postgrad Med J. 16, 207-12.

Kalantar, E., Alikhani,M. Y., Naseri, M. H. andTorabi, V. (2013): Antibiotic resistance patterns of STEC and ETEC strains: A study on frozen foods of animal origin and children with acute diarrhea. J MicrobiolInfect Dis.3, 31-35.

Miri, A., Rahimi, E.,Mirlohi, M., Mahaki, B., Jalali, M. andGhasemianSafaei, H. (2014): Isolation of shiga toxin-producing Escherichia coli 0157:H7/ NM from hamburger and chicken nugget. IntJ Environ Health Eng. 3, 19-23.

Momtaz, H., Dehkordi, F. S., Hosseini, M. J., Sarshar, M. and Heidari, M. (2013a): Serogroups, virulence genes and antibiotic resistance in Shiga toxin-producing Escherichia coli isolated from diarrheic and non-diarrheic pediatric patients in Iran. Gut Pathog. 5, 1.
Momtaz, H., Dehkordi, F. S., Rahimi, E., Ezadi, H. and Arab, R. (2013b): Incidence of Shiga toxin-producing Escherichia coli serogroups in ruminant's meat. Meat Sci. 95, 381-8.

Momtaz, H., Farzan, R., Rahimi, E., Safarpoor Dehkordi, F. and Souod, N. (2012): Molecular characterization of Shiga toxinproducing Escherichia coli isolated from ruminant and donkey raw milk samples and traditional dairy products in Iran. Sci World J. 2012, 231342.

Momtaz, H., Karimian, A., Madani, M., Dehkordi, F. S., Ranjbar, R., Sarshar, M. and Souod, N. (2013c): Uropathogenic Escherichia coli in Iran: serogroup distributions, virulence factors and antimicrobial resistance properties. Ann Clin Microbiol Antimicrob. 12, 1.

Ranjbar, R., Masoudimanesh, M., SafarpoorDehkordi, F., Jonaidi-Jafari, N. andRahimi, E. (2017): Shiga (Vero)-toxin producing Escherichia coli isolated from the hospital foods; virulence factors, o-serogroups and antimicrobial resistance properties. Antimicrob Res Infect Control. 6, 4.

Shahrani, M., Dehkordi, F. S.and Momtaz, H.(2014): Characterization of Escherichia coli virulence genes, pathotypes and antibiotic resistance properties in diarrheic calves in Iran. Biol Res. 47, 28.

Srinivasan, V., Nguyen, L. T., Headrick, S. I., Murinda, S. E. and Oliver, S. P.(2007): Antimicrobial resistance patterns of Shiga toxin-producing Escherichia coli 0157:H7 and 0157:H7- from different origins. Microb Drug Resist. 13, 44-51.

Stewardson, A. J., Renzi, G., Maury, N., Vaudaux, C., Brassier, C., Fritsch, E., Pittet, D., Heck, M., van der Zwaluw, K. and Reuland, E. A. (2014): Extended-Spectrum $\beta$-Lactamase-Producing Enterobacteriaceae in Hospital Food: A Risk Assessment. Infect Control Hosp Epidemiol. 35, 375-83.

Wayne, P. (2012): Clinical and Laboratory Standards Institute (CLSI). Performance standards for antimicrobial susceptibility testing. Twenty-second informational supplement M100-S21. Wayne Pa.

Woo. P. C., Cheung, E. Y., Leung, K. W. and Yuen, K. Y. (2001): Identification by $16 \mathrm{~S}$ ribosomal RNA gene sequencing of an Enterobacteriaceae species with ambiguous biochemical profile from a renal transplant recipient. Diagn Microbiol Infect Dis. $39,85-93$. 